\title{
Parents perceptions of their children body fat percentage and weight
}

\begin{abstract}
Parents' perception of their children's weight and fat percentage may play an important role in developing and maintaining healthy lifestyle. This study was conducted to determine the perceptions of parents of first-grade studentsin a Malaysian urban school setting regarding their children's weight and body fat percent. A descriptive statistic was used in the study. A number of 197 first-grade students participated in this study. The students' anthropometric data,such as weight, body mass index (BMI) and body fat were measured using TANITA TBF-410 GS Body Composition Analyzer. Also The questionnaire for parents used in the study included parents' perception of their child body shape,body weight and eating habit. Results showed a statistically significant correlation between the parents perception and children's real fat percentage with $(\mathrm{r}=-.46, \mathrm{p}<.05)$ for girls, and $(\mathrm{r}=.50, \mathrm{p}<.05)$ for boys while the correlation between girls' weight and their parents perception of weight $(r=-.12, p>.05)$ was not significant. Results of the current study show that girls' parents have misperceive of their children weight. In contrast to the focus of the previous studies on prevalence of overweight among children, most of the underweight children in this study were perceived as normal.
\end{abstract}

Keyword: Perception; Body weight; Fat percentage; Primary school children 